\title{
The Scott/Harker Model of ethical business leadership in the light of an African understanding of human existence
}

\begin{abstract}
Australian business consultant Ted Scott and his colleague, psychologist Phil Harker, have developed a model of ethical leadership in the workplace, involving two basic and contrasting styles of business leadership. Given their location in a wealthy, Western-type society, their model, which this paper describes, generates the following question: Does the model also have validity for Africans in southern Africa? To answer this question, the paper gives a profile of a widely held, traditional African view of human existence and correlates it with the Scott/ Harker model. This leads to the conclusion that the Scott/ Harker model is well suited to the challenges facing African business leaders.
\end{abstract}

Key words: ethical business leadership, Ubuntu, African ethics

\section{Introduction}

Based on extensive experience of successful workplace leadership, Australians Ted Scott and Phil Harker published a view of productive workplace practice, including leadership, in a short book with the title Humanity at work (Scott \& Harker, 1998). The book has since been issued in a revised edition with the title The myth of nine to five: Work, workplaces and workplace relationships (Scott \& Harker, 2002), where their views remain essentially the same. By drawing key parts of those views together, it is possible to construct what I shall call a model of ethical business leadership which resonates strongly with ideas set forth in a recent book of my own and which certainly enriched parts of it. (Prozesky, 2007:76ff)

In view of its emergence in a strongly developed economy, the purpose of this paper is to assess its merits in the context of Africa, much of which is culturally and economically very unlike Australia. To do so, I shall use relevant African traditional understandings of human existence as expounded by a leading young African thinker, Munyaradzi Murove.

The paper has three sections. The first outlines the Scott/Harker model, using their more recent book; the second deals with African traditional views; and the third gives my conclusions.

Martin Prozesky is Director of Compass Ethics and Emeritus Professor at the University of KwaZulu-Natal.

\section{The of the Scott/Harker model of ethical leadership}

The basis of the Scott/Harker model is given in Chapter 5 (Scott \& Harker, 1998:33-42) where a contrast is set up between love and fear in the context of an account of human nature and three great human needs. These are firstly the physical needs we share with all living things in order to survive (and, one might add, thrive in a bodily sense). Then come our social needs, which we share with other animals. As Scott and Harker put it, 'Fulfillment of our social needs allows us to cope emotionally.' (1998:34) Thirdly, there is what the authors see as our uniquely human need, the need for meaning and purpose in life. Interestingly, they call this third need a spiritual need, without necessarily linking it to religion, at least in the usual sense.

Threats to any of these needs evoke fear in us and other animals, which in turn trigger actions aimed at resisting or avoiding the source of the fear. But as humans we are not trapped in an instinctive fear response because of our ability to be aware of ourselves and to make a significant choice about how we will manage ourselves and relate to others.

In the words of the authors, 'the primary motive driving the mind's decision making processes is that of "self-preserving" fear ... As the boundaries of the 'self' expand, however, to take into account the lives of others, the motive may eventually move from fear to love.'

Further on, Scott and Harker state: 'When the individual comes to the realization that self-consciousness implies another level of existence - a metaphysical level - which brings them into union with all others, a fundamental shift in core motive is enabled: the shift from fear to love. Love is the dissolution of the separateness of mankind. When we see the world through the eyes of love, we know that our deepest well-being is enhanced by furthering the well-being of all humanity.' (1998:37f)

Awareness of the possibility of this shift from fear to love as the governing factor in our lives opens the way to what Scott and Harker see as a fundamental choice, namely to make that shift a reality in our lives. It is here, when the choice is made and enacted, that things take on a clearly ethical character. And when people choose to govern their lives through love and not fear, their choice 'allows the development of a mentality of seeking to maximize the quality of collective human life ... This has enormous implications for management who desire 
to raise the potential quality of working life and not just the productive "quantities" in their organizations.' (Scott \& Harker, 1998:40f)

The implications for ethical leadership in business and elsewhere should be clear: leaders can run their organisations with either fear or love as their primary orientation. If they are governed by self-concern and their own egos, the tendency will be to control others. If they have transcended egoism and are genuinely concerned about the well-being of others they will know that those whom they lead will respond far more productively to love than to fear in the workplace. That in turn makes the success of their organisations more likely, especially in the long term.

Such, in summary, is what I am calling the Scott/ Harker model. Now it is time to correlate it with African traditional thinking about human existence.

\section{Human existence in a traditional African perspective}

My account of an African traditional understanding of what it means to be human draws on the work of Munyaradzi Murove and to a lesser extent on that of Augustine Shutte and Mike Boon. Murove's research focuses mostly on southern African traditional cultures, especially those of the Shona in Zimbabwe and on the main strands of South Africa's black African cultures.

In what follows, I accept the general consensus of many scholars in this field, including Murove, that despite local variations, there are some important and basic features of these African world-views that are held in common, making it legitimate to speak of an African understanding of human existence in the singular, as I am doing. At the same time, I need to make it clear that it is sub-Saharan Africa that they have in mind, with special reference to southern Africa. (Murove, 2004)

My purpose in outlining this African perspective on what it means to be human is of course primarily to elicit its ethic, but this can only be done after we have considered the broader African world-view and pattern of living that undergirds it, by focusing on two key concepts: Ukama and Ubuntu. To give an advance indication of what I am about to set forth, let me quote Murove:

'Whilst the Shona word Ukama means relatedness, Ubuntu implies that humanness is derived from our relatedness with others, not only to those currently living, but through the generations, past and future. When these two concepts are compounded in their togetherness, they provide an ethical outlook that suggests that human well-being is indispensable from our dependence on and interdependence with all that exists, and particularly with the immediate environment on which all humanity depends.' (Murove, 2004:195)
At least in South Africa, the African principle of Ubuntu, a Zulu and Xhosa word, and its ethical implications are well known. The special merit of Murove's work is to link it with the Shona concept of Ukama by showing that the latter gives Ubuntu an important ontological basis and clue to human flourishing. I will follow Murove's approach and deal first with Ukama.

Ukama stands for the conviction that reality is inherently relational. It means not only that people will only find their true identity in relationship with other people, both those now alive and those who live in the spirit world, a belief in the watchful presence of the ancestral spirits being universal in African traditional cultures, but - importantly - with nature as well. As such, Ukama can be seen as a highly inclusive concept applying to all that exists. (Murove, 2004:198)

An important implication for what it means to be human follows from the principle of Ukama. In the words of Murove: '... Ukama implies that there are no entities that are self-sufficient and enjoy existence independently from other entities.' (2004:202 (author's emphasis))

Turning now to Ubuntu, a term that is mostly translated as 'humanness', Murove writes as follows:

'... the concept of Ukama offers a general scope for understanding African ethics. In Ukama relationality permeates all spheres of existence. However, this relationality is further concretized in Ubuntu because the main presumption in Ubuntu is that the individual is indelibly associated with the community, and can only flourish in Ukama within the community. Ubuntu implies the inherent African appreciation of relationality or Ukama. This appreciation carries with it the exhibition in the individual's behavior of those socially condoned moral qualities or virtues that make the individual's behavior acceptable to and supportive of the community ...' (Murove, 2004:207 (author's emphases)). Quoting Mvume Dandala a bit further on, he adds that Ubuntu '... becomes a statement that levels all people. It essentially states that no one can be self-sufficient, and that interdependence is a reality of all.' (Murove, 2004:208)

The South African philosopher Augustine Shutte has given a handily concise interpretation of the ethic implied by Ubuntu in a recent book, explaining this concept as 'the insight that persons depend on persons to be persons.' (Shutte, 2001:25) He adds: 'The goal of morality according to this ethical vision is fullness of humanity; the moral life is seen as a process of personal growth. And just as participation in community with others is the essential means to personal growth, so participation in community with others is the motive and fulfillment of the process. Everything that promotes personal growth and participation in community is good, everything that prevents is bad.' (Shutte, 2001:30) 
These words should bring the Scott/Harker model of ethical leadership to mind, as it emphasises leaders who transcend egoistical motivations in order to serve the interests of their organisations and followers.

In sum: deeply embedded in the consciousness and way of life of Africans in whom the traditional worldview and culture remain a reality, even if only partially, is the conviction that the individual person can only flourish in and with other people, and never in separation from or indifference towards them, because relatedness Ukama - is the way things are. Clearly, there is no place here for the kind of Western individualism that regards the individual as sovereign and self-sufficiency as a vitally important goal.

The question that arises for those of us who live and work in Africa but also seek connection with other parts of the world, like the world of Ted Scott and Phil Harker with its business success, is this: is the Scott/Harker model of an ethical business leader compatible with Africa's beliefs about what it means to be human, and above all with Africa's conviction that human thriving is only possible when individualism is repudiated in favour of communitarian values and practice?

This question brings me to the third and final part of the paper.

\section{Can African business embrace the Scott/Harker model?}

My answer is that African business can indeed embrace the Scott/Harker model of ethical leadership and, what is more, draw encouragement from its practical success in business. To explain why I reach this conclusion I must introduce a feature of Africa's view of human existence that I have held back so far.

Cultures based on Ukama/Ubuntu do not turn people into robots or clones, obediently repeating traditional patterns of behaviour in cultural lockstep, without interest in or ability to foster creativity, enterprise and innovation.

On the contrary, they greatly prize human fulfillment through personal vigour, as can be seen from the Sotho/ Tswana concept of seriti and its Nguni equivalent of isithunzi, often translated as 'vital force' (Thorpe, 1991; Boon, 1996). In referring to this concept, it needs to be noted that it is debated by other African scholars, a debate which lies beyond the scope of the present paper.

Augustine Shutte provides a handy account of this feature of Africa's beliefs about human existence, quoting Gabriel Setiloane (1986) as follows:

'... the human person is like a live electric wire which is forever exuding force or energy in all directions. The force that is thus exuded is called seriti. It is like an aura around the human person, an invisible shadow or cloud or mist forming something like a magnetic or radar field. It gives forth into the traffic or weltering pool of life in community the uniqueness of each person and each object ...' (Shutte, 2001:21f (emphasis added)).

In other words, Ukama/Ubuntu means that rich, personal creativity, like rich personal well-being, is only possible when individuals enjoy the supportive resources of a healthy context made up of other vigorous, fulfilled people and nature, in an ongoing process of mutual enrichment. Without that, individuals will wither.

What, then, makes the Scott/Harker model one that Africans can embrace? It is firstly their insight that personal growth and fulfillment for all of us depend on a move from fear to love and from egoism to inclusiveness of concern. In their own words: 'When we see the world through the eyes of love, we know that our deepest well-being is enhanced by furthering the well-being of all humanity.' (2002:37f (emphasis added)) What is this, if not an affirmation of the principle of Ubuntu?

My second reason for seeing the Scott/Harker approach as one that Africans can (and should) embrace comes from the view of leadership that flows from their work. What they in effect say is that true leaders are those who transcend egoism and individualism in favour of a genuine commitment to furthering the interests of those whom they lead. What is this, if not an Ubuntu model of leadership in business and any other workplace, because, quite plainly, it is a way of saying that to succeed as a leader, you must welcome and work with your inter-relatedness with others your Ukama - serving those whom you lead and not exploiting them?

My final point is that the Scott/Harker model will be enhanced by the African principles of Ukama and Ubuntu because they will give it an ontological underpinning, in the form of the principle of universal relatedness, that explains just why the shift from fear to love works in practice, in business as elsewhere: it works because the inclusiveness that love implies and fosters is how things really are, not the exclusiveness of fear, egoism and topdown control.

In short, the Scott/Harker model and the Ukama/ Ubuntu world-view are mutually enriching. That the former arose in a developed world economic context while the latter is rooted in a subsistence economy and culture suggests that they could well find acceptance just about anywhere.

\section{References}

Boon, M. 1996. The African way: The power of interactive leadership. Sandton: Zebra Press.

Bujo, B. 2001. Foundations of an African ethic: Beyond the universal claims of Western morality. New York: The Crossroads Publishing Company. 
Murove, M. 2004. An African commitment to ecological conservation through the concepts of Ukama and Ubuntu. Mankind Quarterly, xlv(2) Winter: 195-215.

Prozesky, M. 2007. Conscience: Ethical intelligence for global well-being. Pietermaritzburg: University of KwaZuluNatal Press.

Scott, T. \& Harker, P. 1998. Humanity at work. Luscombe, Queensland: Phil Harker \& Associates.

Scott, T. \& Harker, P. 2002. The myth of nine to five: Work, workplaces and workplace relationships. North Sydney: Richmond Ventures Pty Ltd.

Setiloane, G. 1986. African theology. Johannesburg: Skotaville. Shutte, A. 2001. Ubuntu: An ethic for a new South Africa. Pietermaritzburg: Cluster Publications.
Thorpe, S.A. 1991. African traditional religions. Pretoria: University of South Africa.

\author{
Address correspondence to: \\ Martin Prozesky \\ University of KwaZulu-Natal \\ Pietermaritzburg Campus \\ Private Bag X01 \\ Scottsville, 3209 \\ South Africa
}


Reproduced with permission of the copyright owner. Further reproduction prohibited without permission. 